\title{
Global mHealth policy arena: status check and future directions
}

\author{
Donna M. Malvey ${ }^{1}$, Donna J. Slovensky ${ }^{2}$ \\ ${ }^{1}$ Department of Health Management and Informatics, College of Health and Public Affairs, University of Central Florida, Orlando, Florida, USA; \\ ${ }^{2}$ Department of Health Services Administration, School of Health Professions, University of Alabama at Birmingham, Birmingham, Alabama, USA \\ Contributions: (I) Conception and design: All authors; (II) Administrative support: None; (III) Provision of study materials or patients: None; (IV) \\ Collection and assembly of data: None; (V) Data analysis and interpretation: None; (VI) Manuscript writing: All authors; (VII) Final approval of \\ manuscript: All authors. \\ Correspondence to: Donna M. Malvey, PhD. HMI Department, University of Central Florida, 4364 Scorpius Street, Orlando, Florida, USA. \\ Email: donna.malvey@ucf.edu.
}

\begin{abstract}
In this review, we examine an important piece of the mHealth puzzle that has received scant attention-health policy. The question is whether health policy ultimately will serve to unite nations in advancing global mHealth or, as Mars and Scott suggested in 2010, keep nations isolated and ultimately making their policy decisions in "eHealth silos". Such a non-collaborative approach seriously hampers the potential for using mobile health technologies to deliver health care across borders, assuring individuals access to affordable, convenient, and quality healthcare in underserved regions. From a global perspective, mHealth policy review is difficult as some important policies may be subsumed in comprehensive planning and strategy documents. Political, environmental, economic, organizational, and technology disparities across nations represent a significant impediment to developing mHealth products and services that can be deployed globally. To date, there is modest evidence that such challenges are being addressed. Even though payers can encourage adoption of mHealth with financial incentives for use, it appears that payment or reimbursement tends to be a roadblock for almost all nations, whether they are emerging or developed. If payment for mHealth services is not guaranteed, business models will not be sustainable and providers will have fewer opportunities for scalability. Furthermore, because mHealth policies typically are subject to some type of government scrutiny and oversight, many product developers and entrepreneurs may turn elsewhere for their investments. Global resource scarcity also challenges optimal mHealth deployment, and governments seek to ensure improved population health outcomes as return on their mHealth investments. Unfortunately, such justification is difficult as evaluation methods simply have not kept pace with mHealth technology capability. Requisite measurement tools are sorely lacking when it comes to evaluating efficacy of mHealth interventions, due in part to insufficient research to inform development of needed measurement tools. Because most robust mHealth research trials have been conducted in the developed world with its impressive technology infrastructure and not in developing nations where the health needs are greatest, evaluation of mobile technology intervention from a global perspective tends to be insufficient to inform policy decisions.
\end{abstract}

Keywords: mHealth; health policy; global health policy

Received: 22 June 2017; Accepted: 06 September 2017; Published: 22 September 2017.

doi: $10.21037 /$ mhealth.2017.09.03

View this article at: http://dx.doi.org/10.21037/mhealth.2017.09.03 


\section{Introduction}

In mHealth: Transforming Healthcare (1), we examined the trends of mHealth globally and offered some predictions regarding challenges and opportunities for mHealth adoption throughout the world. At the time, we gave much attention to the intersection of healthcare and business models, concluding that development of business models constituted a major challenge for the future of mHealth globally. We fully expected to see the rise of public-private partnerships that would benefit patients, governments, entrepreneurs, and developers. However, ensuing reality has not confirmed our expectations. We also anticipated that emerging health policy would promote global mHealth deployment, which we define as "mobile technologyfacilitated health interventions that can be deployed across borders (domestic or international), and that can be feasibly scaled for widespread implementation in diverse settings". Instead, it appears that health policy generally lags behind the potential for expansion of mobile health technologies and often is an impediment rather than a facilitator for optimization. Health policies, and indeed health care delivery, traditionally have been circumscribed within countries, states, or other geo-political regions. However, the nations (and peoples) of the world are increasingly interconnected, as enabling technology has facilitated travel, communications, trade, healthcare, and other social and economic transactions.

Thus, current evidence suggests that technology is not the complicated piece of the global mHealth puzzle. We submit that, currently, the more complicating factor is health policy. The question now at hand is whether health policy ultimately will serve to unite nations in advancing global mHealth or, as Mars and Scott (2) suggested in 2010, keep nations isolated and ultimately making their policy decisions in "eHealth silos". Such a non-collaborative approach seriously hampers the potential for using mobile health technologies to deliver health care across borders, assuring individuals access to affordable, convenient, and quality healthcare in underserved regions.

Consequently, we believe it is time to take a more focused look at the role of health policy in advancing global mHealth. This review seeks to extend the research conducted by Mars and Scott (2) in the early 2000s and reported in 2010. Specifically, we examined and report the current state of global mHealth policy in three areas:

* Key factors that have the potential to influence development and implementation of global
mHealth policies.

* Emerging, existing, and future challenges, ranging from demographics to resource scarcity, to regulatory, payment, and security issues.

- The state of global mHealth policy today and a desired future.

It is not the intent of this review to examine health policy distinctions between developing and developed nations as this would require a much lengthier paper, or possibly a set of papers, and might be impractical in terms of availability of this type of information. Differences and distinctions between developing and developed nations are noted within the context offered for discussion about the state of a global policy framework.

\section{Key factors influencing mHealth policy decisions}

Key factors that have potential to influence development and implementation of global mHealth policies include who makes these policy decisions, the amount of and goals for government spending, mHealth itself, and population health initiatives. Other factors certainly have a role, but these are most influential.

The question "Who makes health policy decisions?" does not have a straightforward answer, even in highly regulated countries. Most health policy decisions, including those associated with mHealth, are not made collaboratively considering all stakeholders. Instead, they often are made at a variety of governmental levels ranging from regional through national, and may even be promulgated by nongovernmental agencies. The policies often are limited in scope, serving to address a specific need, such as controlling resources within a limited program, or address a specific population, such as geographic regions or age categories. Often health policy formulation on similar topics with potential for conflicting implementation occurs in countries that are geographically or politically isolated from one another. Policies developed using non-collaborative approaches likely will inhibit mHealth's potential for crossborder interventions, a necessary precursor to truly going global. However, collaboration doesn't always lead to successful implementation of policies. Consider the efforts of the European Union (EU) toward achieving global mHealth.

The EU's proposed cross-border initiative is intended to support free patient mobility; that is, the ability of patients to seek out and receive care in other Member States and have the cost of that care reimbursed. A March 2011 
directive of the European Parliament and of the Council of the EU on the application of patients' rights in crossborder healthcare attempted to explain how the crossborder healthcare initiative would work. The directive addressed limitations, numerous regulations, and a complex reimbursement framework that urged cost effectiveness along with suggested options that some Member States might choose to cover additional costs, such as travel. A wide range of topics were covered, including privacy and security of data transmission, definitional rights of patients to free mobility care and to eHealth services, along with Member States' roles and responsibilities, and issues of prior authorization (3). To date, there has been little evidence of progress in moving the initiative forward. A May 2015 survey reported that "fewer than 2 out of 10 respondents felt well-informed about their rights in crossborder healthcare" (4). It remains to be seen if the crossborder initiative will be successfully operationalized.

A challenging aspect of operationalization will likely be the impact on national health systems as patient mobility might vary between Member States or between regions within a Member State. It will depend on factors such as geographical location, language barriers, location of hospitals in border regions, or the size of the population and healthcare budget, as well as establishing accountability and responsibility across EU Member States. Finally, given Brexit, the EU will face omission of one of the largest Member States. Should other Member States withdraw from the EU as well, as speculated, there will be enormous holes in the cross-border initiative.

Vytenis Andriukaitis, the EU Health and Food Safety Commissioner, is part of a commission project team that in early 2015 adopted a digital single market strategy that included a focus on eHealth. Andriukaitis called for a paradigm shift in health policy thinking, away from a cost focus toward preventive healthcare, including adopting eHealth as a key priority to achieve population risk reduction through increased access to healthcare. The Commissioner believes digital technology can improve healthcare quality and safety while enhancing the performance and sustainability of healthcare systems across the EU. He cited the need to address legal and institutional obstacles that deter cross-border telemedicine services, and to adopt a "health in all polices" approach (5).

Currently, there is little evidence of mHealth providers practicing across domestic and international borders, except in a few cases where limited agreements exist. In addition, political power imbalances potentially restrict cross- border initiatives. There is some evidence of cross-border telehealth in Latin America, where six countries engage in such practices (2).

The World Health Organization (WHO) has long been an advocate for using formal planning processes to design and implement health policies. Health 2020, which was adopted by the 53 Member States of the Region for Europe in September 2012 lays out such a framework (6). It gives policy-makers a vision, a strategic path, a set of priorities and a range of suggestions about what works to improve health, address health inequalities, and ensure the health of future generations. It identifies strategies for action that are adaptable to the many contextual realities of the WHO European Region.

However, as with many external globalist organizations such as the WHO, which exist independent of a national structure, there is often little resulting action as it is up to the Member nations to follow through on implementation and further development. There are no consequences for countries or regions that fail to implement the strategies. There is also little funding available for countries that are resource-challenged or face competing priorities. Consequently, absent external support, the strategies identified by WHO will remain unrealized for many.

A Population Health focus is becoming ubiquitous, at least in intent. Most countries are searching for means to address the cost curve, including employing innovative approaches to managing the health of a population. Under these models, providers are designated responsibility for the full spectrum of health needs of a population compared with the previous focus and payment for delivering episodic care. It is incumbent on providers to realize they need to know about their population's health risks and requirements even before they get sick and seek care. Providers are also tasked to measure and improve care processes for their overall population (7).

However, if all participants in population health initiatives (ranging from patients to providers to payers, and including governments) are to be successful at managing population health, then health and social care systems will need to join forces. Furthermore, both public and private sectors will have to transition financial incentives to prevention and assuring that improved health outcomes occur. However, balancing the potential benefits of population health management with the practicalities of implementing, funding, and delivering such models remains in the early stages (7).

Health care is one of the largest industries in the world, 
representing almost 10 percent of global GDP (8). Global healthcare spending is expected to grow at $5.2 \%$ annually through 2018. However, the percentage of GDP spent on global healthcare is expected to decrease from $10.6 \%$ in 2014 to $10.3 \%$ in 2018 (9). Because governments fund much of healthcare sector operations, challenging economic conditions make it difficult for governments in many of the world's regions to devote the necessary financial resources to handle expanding health care demands, especially when they are coupled with ever-rising costs. The Deloitte Report notes improvement in the US economy, but less gain in other countries, citing "sanctions and falling oil prices in Russia; a stagnating economy in Japan; significant growth slow-down, rising debt levels, and currency devaluation in China; and recession and inflation in some Latin American countries" as examples (7).

In 2014, we wrote that mHealth would play a pivotal role in transforming health care into a more efficient, patient-centered system of care, largely because mHealth could offer both patients and providers real-time access to information to support engagement (1). Estimates suggested that by 2015 , over 500 million of a total 1.4 billion smartphone users worldwide would be using mHealth apps; by 2018, 50 percent of the 3.4 billion mobile device users would have downloaded one or more mHealth apps. mHealth applications can range from basic apps that record and report on such things as user-input daily calorie intake to more advanced mHealth apps where portable devices measure temperature, heart rate, blood oxygen levels, respiratory rate, ECG, and blood pressure, and transmit the data to a mobile device (10).

\section{Existing, emerging, and future challenges}

Existing, emerging, and future challenges, ranging from demographics to resource scarcity, to regulatory, payment, and security issues, continue to inhibit the development of global mHealth policy. Globally, countries confront similar health challenges in terms of aging, chronic and degenerative diseases, communicable diseases, and provider shortages, all of which could be mitigated by deployment of mobile health technologies. However, there seems to be a lack of wherewithal in terms of means, ability, and finances to support expansion and sustainability of mHealth.

Even though mHealth is thought to have the ability to transcend sociopolitical boundaries and potentially create a borderless world for health delivery systems, the health policy required to guide and fulfill such development is limited and late appearing, even in developed nations. With regard to the developing world, health policy makers in those nations face critical policy challenges because of resource scarcity and competing priorities for such basic life needs as adequate drinkable water and food, and education. Of particular concern is a widening disparity between those with and without access to electronic information and communication tools (2).

Across the globe, mobile phones are a means to engage patients in health promotion and disease management initiatives, ranging from individuals suffering with HIV/ AIDs to pregnant women and mothers of newborns. The mobile phone is an inexpensive and easily deployed approach to providing just-in-time health information and access to disease monitoring and some forms of primary care. Mobile phones-and the apps that run on them-have definitely gone global. However, health policy is required to determine the future direction of health initiatives to assure continued successes and expansion of the types of services available (1).

Despite the fact that mobile phones are widely dispersed in developing nations, there are challenges associated with costs of owning and using phones, including the issue of reliable battery power. We earlier wrote that battery power was a problem that major corporations such as Motorola were responding to, especially for remote areas in such places as Sub-Saharan Africa (1). The problem apparently persists with insufficient progress toward resolution, but there is some evidence of change occurring.

For example, northern India areas in the Himalayans, such as Jammu and Kashmir, Himachal Pradesh, and Uttarakhand, have very poor cellphone coverage. The Indian Space Research Organization (ISRO) provides satellite links to connect the telemedicine centers in these areas to hospitals in Delhi, Chandigarh, Srinagar and Puducherry. Recently, the Indian Union ministry of health proposed to expand the rural telemedicine network via collaboration with ISRO. Furthermore, the government has stated an intention to connect 41 medical colleges across India so that medical students can have access to specialist lectures in top medical institutes (11).

In developing countries, health innovations likely will need to come from the private sector, as most public resources are focused on providing quality health services through proven mechanisms, devoting little of their resources to developing innovations. However, given the amount of health information generated around the world from multiple disparate sources, analytics may help to guide public sector innovation efforts (7). 


\section{Demographics}

Population aging is accelerating rapidly worldwide. Increased life expectancy-up from an estimated 72.3 years in 2014 to 73.3 years in 2019-will bring the number of people aged $65+$ worldwide to over 604 million, or 10.8 percent of the total global population. That number is anticipated to be even higher in Western Europe (nearly 21 percent) and Japan (28 percent) and unfortunately, it appears that health quality is not keeping pace with longevity, nor is the development of age-appropriate health policies and services (7)

A comprehensive Deloitte report (7) described change as "the new normal for the global health care sector". All players in this dynamic environment, including payers, governments, providers and other stakeholders, are tasked with creating processes and systems to deliver care that achieves what amounts to a trifecta of goals: care that is effective, efficient, and equitable. Achieving these goals in an environment that is experiencing profound shifts in business, clinical, and operating models will be enormously challenging. The effects of these environmental shifts are compounded by other important and dynamic factors categorized by many scholars and effectively summarized in the Deloitte report: an aging population; better chronic disease management; increased focus on value-based care; new and differing payment models; quality measures affecting reimbursement; better informed and empowered consumers; and technology innovation $(7,12)$. These factors, independently and in conjunction, are leading to rising system-level costs and significant increases in spending levels for care provision, infrastructure improvements, and technology innovations.

\section{Resource scarcity}

Scarce resources, especially in the developing world, challenge politicians who must allocate ever-shrinking budgets across the need for mHealth and its infrastructure to basic necessities such as potable water, medicines, paying health workers, and conducting disease surveillance. Decisions about budget allocations are reflected in the dearth of mHealth policies or sustainability of mHealth activities in developing nations. Developing nations find themselves disadvantaged not just in terms of economic and technology resource capacity, but also human resource capacity. Their ability to take advantage of mHealth or formulate policies to advance its adoption does not appear promising (2).

Yet, it is these developing nations that need mobile health technologies most to bridge gaps in terms of the critical lack of health care resources and infrastructure, especially in rural areas. And, policymakers must recognize the potential of mHealth to provide access to care, especially given the disease burden they carry and the need for continuing surveillance of chronic and emerging disease patterns. For example, in India, a country with a large proportion of its population living in rural areas, with poor affordability and limited access to health care services, the potential benefits are particularly powerful. The innovative use of technology can help to maximize India's limited health care resources at a lower cost (7).

In the US, attempts to bring health costs under control have required a shift in reimbursement systems from feefor-service care that promotes delivering volumes of services, to value based care (VBC) that aims to deliver specific types of care needed efficiently (13). Unfortunately, there is no roadmap to achieving VBC despite much scholarly inquiry and operational analysis. In addition, given that not all US healthcare markets are the same, they pose different challenges to VBC, and many unknowns arise (14). Under the Affordable Care Act, there were incentives for patient engagement and satisfaction, which were expected to improve health outcomes as well as reduce expenditures. However, because the US healthcare system is a patchwork of political accommodation (15), many intended benefits have not been realized.

\section{Regulation}

Our earlier mHealth research revealed that some experts felt that developing countries are experiencing a leapfrog phenomenon in which mHealth adoption occurs on a faster and grander scale than in developed countries because they confront less opposition and infrastructure barriers such as entrenched bureaucracies and legacy health systems. We noted that in developed nations government oversight often limits progress, or at least the speed with which progress is allowed to occur, and can also preclude adoption of innovations through extensive regulatory and compliance controls (1). This also could help explain why studies have shown less engagement in mHealth activities among developed nations (16).

But, we must also face reality. Numerous developing countries are disadvantaged in their efforts to deliver health care services, especially in rural areas, by an acute lack of 
resources and infrastructure. For example, sixty-two percent of Africa's entire population resides in rural areas, where there is poor access to medical facilities. There also exists a continual power crisis in some areas of Africa. India, with an average 0.7 hospital beds per 1,000 of its population, has a patchy public health care system with underfunded hospitals and clinics. The country's limited health care resources are heavily skewed towards urban areas (65-70 percent of infrastructure and manpower), while $\sim 70$ percent of the population resides in rural areas (7).

There also is continued need for improved health care infrastructure in China's tier II and III cities, defined as those cities with populations between 150,000 and 15 million, i.e., all cities except Beijing, Chongqing, Shanghai, Tianjin, or a rural area. Even though the government has invested a huge amount of money in medical equipment and physical facilities, these cities still lack adequately trained clinical manpower to diagnose and treat patients using the technology and facilities in which they have invested (7). In addition, there appear to be formidable barriers to adoption of mHealth, including bureaucratic impediments fostered by governments endeavoring to protect their citizens from harm, but ultimately possibly contributing to a stalemate in the actual expansion and scaling up of mobile health technologies (2).

Implementation will depend not only on what motivates the end users, the patients and providers, but also on payment mechanisms. Payers may be either public or private insurers that encourage adoption of mHealth with financial incentives for use. Payment is a major issue for US providers, and US legislative bodies at both the state and federal level have yet to resolve reimbursement challenges for both private and public insurances such as Medicare and Medicaid. However, this inability to find resolution to payment is clearly not unique to the US. Payment is another policy that confronts the EU. Failure to address and resolve issues of provider remuneration imperils the free patient mobility and cross-border initiatives (2).

System fragmentation is a barrier that must be resolved if mHealth initiatives are to achieve their potential or even reasonable success. Fragmentation is often considered a problem for developed nations due to the volume of market players and differing incentives. In the US, medical infrastructure is enormous, conservative, and resistant to change. System fragmentation is often identified as a major cause of access, cost, and quality problems. However, the EU, which promotes a highly centralized approach along with regulatory compliance extending across all members, has not yet succeeded in implementing their digital initiatives across all member nations.

\section{Current state of global mHealth policy and a desirable future}

Despite the lack of policy infrastructure and established inter-country relationships, mHealth as a means of delivering healthcare is expanding worldwide, albeit primarily through local initiatives. Healthcare providers and scholars alike generally recognize the potential for even greater expansion of mHealth programs to improve individual access to a range of healthcare services. Yet we do not know whether this potential will be realized because we do not know to what extent mHealth can be scaled and sustained for a long future. What we do know is that mobile health technologies tend to require less financial investment and infrastructure than many other health system transformative efforts, both factors that facilitate scaling up and widespread deployment of mHealth. Even in developing countries, such factors suggest mHealth deployment goals appear achievable.

However, what appears achievable often remains unrealized without ensuring necessary infrastructure, which would include enforced policies and appropriate regulation. Effective policies can fund programs, or remove funding and distribute it to higher priority goals. Health policies can incentivize certain healthy behaviors or dis-incentivize unhealthy ones. And, good policies can also be used to reform or redesign existing systems.

Information on mHealth policies in various countries is not readily available, due in large part to the fact that the term 'policy' is fluid, in that it can be viewed as something as informal as a plan or goals for a program, or formalized and enacted laws. Mars and Scott's (2) investigation of global e-health policy found that most policies are made in isolation, by various professional organizations, health institutions, and governments. Thus, there is little transparency or standardization across policies globally, which will deter cross-border initiatives such as those put forward by the EU in efforts to establish free mobility patient care. While some encouraging efforts have been reported, many challenges remain.

\section{Example initiatives}

In the US, a developed nation, telemedicine is a service delivery option in most regions. According to a survey 
of healthcare executives, the vast majority of leaders (90 percent) report that their organizations have or are developing a telemedicine program (17), and they consider the ability to offer meaningful telemedicine services essential to their organization's success. However, reimbursement for telemedicine remains an uphill battle, as indicated by 41 percent of respondents who said they are not reimbursed at all for telemedicine services, and 21 percent who reported receiving lower rates from managed care companies for telemedicine than for in-person care (18). Additionally, licensure requirements often prohibit clinicians from providing services across state lines without reciprocal licensure. From a policy perspective, little attempt at national legislation is expected. However, the American Medical Association is advocating for interstate compacts to enable health professionals to practice across state lines (19).

India, a developing country, considered health laws that would address international practice of telemedicine across borders and resolve some cross-border issues by adopting reciprocity, registration, and licensing agreements to facilitate telehealth (2). It is not evident that these laws were promulgated. In July 2016, a new telemedicine hub began operations near Sheshnag Lake in Jammu and Kashmir, increasing the number of such telehealth centers to 105 (11).

China, also considered a developing country, but whose economy is on the precipice of eclipsing that of the US, is shifting its focus from increasing health care service volume to enhancing provision efficiency, and is making strides in providing higher-quality care. Current government reform efforts are centered on reducing unnecessary drug usage, upgrading public hospitals, and channeling private capital into health care provision and health insurance. The government also strongly supports new digital health technologies as a way to improve efficiency (7). China issued initial telemedicine guidelines in 2014, but continues to struggle with regulatory flux, changing government priorities, and unclear national policies for competition from foreign providers (20). The size of unmet medical need in China impels the use of telemedicine and other forms of mHealth, but significant barriers to effective deployment remain.

In the Mideast, the Gulf countries are experiencing a tremendous increase in demand for health services. Across the Gulf countries, governments are creating new initiatives for telemedicine and are seeking private partners to join with them to maximize their investments. However, inconsistent regulation of telemedicine services appears to be inhibiting growth. For example, there is much variability in availability of telemedicine services, and in some cases, in-person consultations are still required for prescribing medications. Other issues with licensing of diagnostic imaging facilities include unclear regulations regarding outsourcing (21).

\section{A desired future state}

One possible future for mHealth is that it will continue to foster increased access to care in emerging countries while transforming the developed nations' large and costly health systems into affordable, prevention-based and patient-focused delivery systems-providing low-intensity services that may decrease the need for more invasive medical engagement. In this future scenario, health policy supports increased global access such as the successful implementation of the EU's cross-border initiative with payment mechanisms that permit free patient mobility across nations.

Our research supports the findings from Mars and Scott's research (2), indicating that few visible and actionable policies intended to facilitate deployment of mHealth interventions across geographic boundaries exist. Thus, we also must consider an alternative possible future for mHealth, one in which health policy continues to lag behind the rapid pace of mobile health innovation and technology and subsequently negatively impacts deployment and sustainability because there is little to no oversight and guidance in place.

Nations cannot allow a health policy vacuum to persist if interoperable global mHealth can produce meaningful improvement in the health of populations worldwide. In light of this conclusion, we find ourselves speculating about a "desired future state" for mHealth policy and returning to the influential factors for effective policy formulation to inform our speculation.

First, we consider the types of health policy needed to achieve interoperable global mHealth. Frenk (22) concisely articulated four major levels of health policy, each with its own goals and issue responsiveness: systemic, programmatic, organizational, and instrumental. He concluded that any effective health system reform would need to consider policy formulation at all four levels. We agree that the ideal global mHealth policy infrastructure would require nations to consider the spectrum of guidance needed-from regulation at the system level, through defining specific programs and operational practices, to evaluation and 
Table 1 Recommended policy levels to promote global mHealth

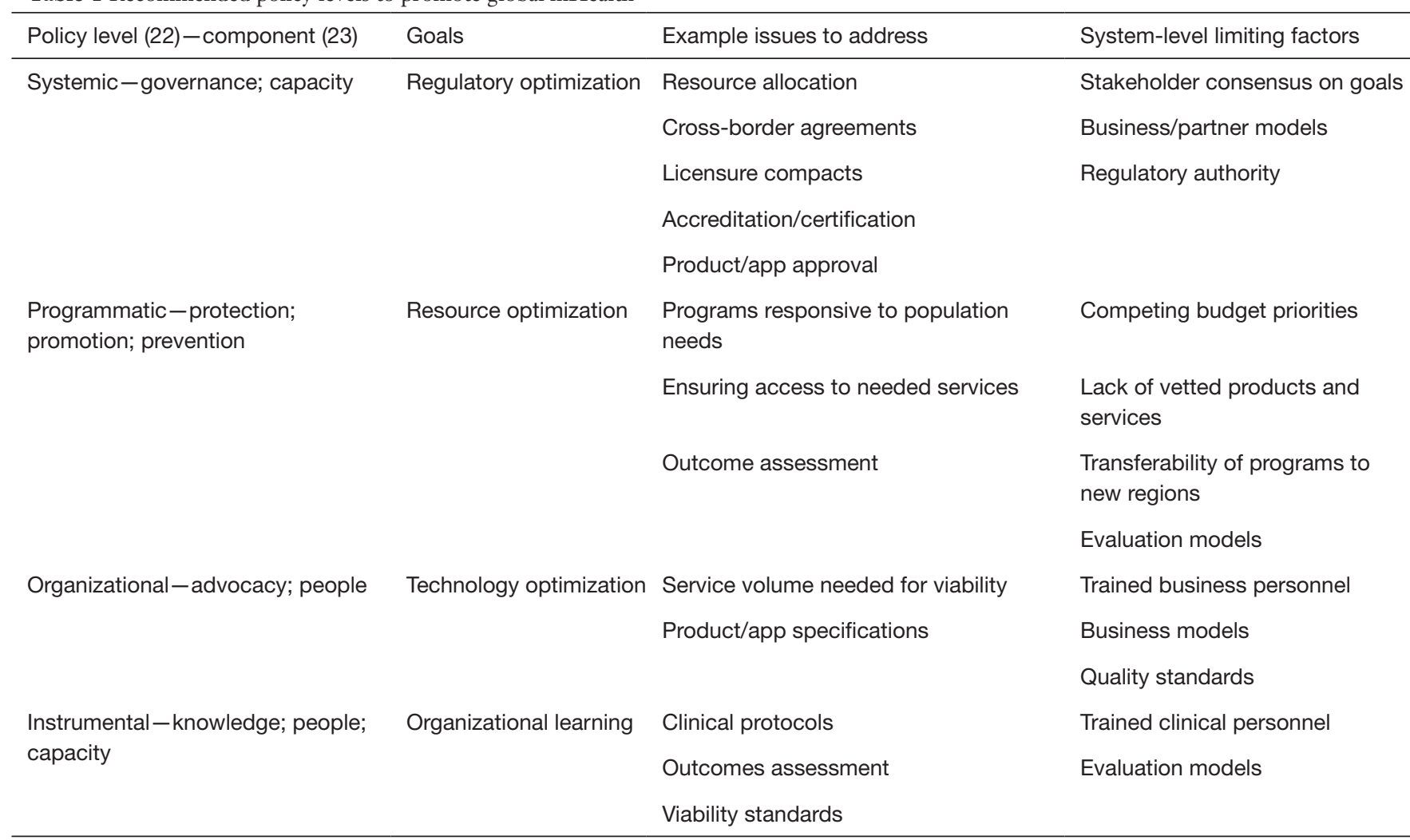

continual innovation. Table 1 illustrates key policy issues that should be addressed at each level, and suggests some factors that may inhibit successful formulation.

More recently, The Commonwealth, a 52-country intergovernmental member organization representing 2.4 billion people, proposed a "flexible health policy framework for tools that can be applied to different countries and settings to strengthen health systems, including for assessment, planning, training, evaluation, and accreditation" (24). The framework, available online at The Commonwealth's Health Hub (23), is graphically represented as a multi-layered, interconnected entity that includes eight key components: governance; knowledge; protection; promotion; prevention; people; advocacy; capacity.

The policy framework, designed to support the World Health Organization's framework for design of sustainable public health systems, is a first step in developing and promoting comprehensive tools, such as a policy toolkit and policy briefs. The framework uses general language enabling its application across diverse systems, modalities, and programs. Table 1 shows levels of policy where these components are most relevant.

Second, we consider who should establish global mHealth policy. Too often, policies are formulated by a group of individuals who have a keen interest in the intent of the policy based on how it will affect their scope of responsibility, but who may be insufficiently knowledgeable about the full spectrum of environmental influences political, social, economic, legal or regulatory, technological, and even competitive forces-that should guide policy development. Even within countries, policy formulation is fragmented and often divisive and international approaches are inherently more complex.

Implicitly, policies are promulgated by parties with the authority and resources to enforce them. As we stated previously, "policy" is a fluid term, and may emanate from many sources and may have variable scope and effect. Within countries, government-defined agencies are typically responsible for the most visible, impactful health policies. By extension, consortia of purposefully-selected existing agencies could be effective in formulating policies to be prescribed for the represented countries. Possibly, The Commonwealth's model (24) of equality among all 
members regardless of size or economic impact is one approach to ensuring each country's needs and limiting factors are considered.

Finally, we suggest that information-sharing and partnering can help to reduce operational and regulatory risks. Some countries are working across governments and agencies to promote a more systematic approach to regulatory rule-making, monitoring, and enforcement. As a cautionary note, the inability to create and sustain health policies that will support and advance mHealth is not unlike the ethics conundrum in which bio-ethicists continue their challenge to formulate ethical polices to match the rapid development and deployment of medical innovations, especially in such areas as stem cells and genomics. The capacity to manipulate human DNA, whether it be for determining gender or other traits of human offspring or cloning of body parts, demonstrates how technology is testing our ability to cope with unprecedented and often unexpected clinical innovations. Similarly, mHealth appears to be testing the ability of our governments to confront the profound changes that mobile health technologies create.

In addition, similar to developed nations, developing nations confront mHealth policy issues related to data security, licensure, and patient confidentiality and privacy that represent major obstacles. Because extant international best practices may be inappropriate for furnishing adequate guidance for these countries, there is the potential of formulating practices that are specific to developing nations. However, doing so could result in a two-tiered system of best practices that may fuel divisions between developed and developing nations (2).

In conclusion, we believe that nations cannot allow a global health policy vacuum to persist, given our expectations that interoperable global $\mathrm{mHealth}$ can produce meaningful improvement in the health of populations worldwide. Policy formulation, which is inherently challenging, is more complex when multiple states or nations seek to achieve a common goal despite their disparities. Evidence suggests that governments can impede or facilitate global policy, and resulting bureaucracies can also impede private sector initiatives, even those with substantial financial investment capability. Strong, credible policy advocates are needed to initiate local efforts that can be leveraged to build more extensive partnerships and collaboratives to address the persistent problem of funding mHealth as a delivery model. Funding solutions are a necessary precursor to expanding mHealth to global delivery, and must be addressed in all planning, whether strategic or operational.

\section{Acknowledgements}

None.

\section{Footnote}

Conflicts of Interest: The authors have no conflicts of interest to declare.

\section{References}

1. Malvey DM, Slovensky DJ. mHealth: transforming healthcare. New York, NY: Springer (Business and Economics Division), 2014.

2. Mars M, Scott RE. Global E-health policy: a work in progress. Health Aff (Millwood) 2010;29:237-43.

3. Directive 2011/24/EU of the European Parliament and of the Council on the application of patients' rights in cross-border healthcare. Official Journal of the European Union, 2011, March 09. Available online: http://eurlex. europa.eu/LexUriServ/LexUriServ.do?uri=OJ:L:2011:08 8:0045:0065:en:PDF

4. European Patients Forum. Directive on Patients' Rights in Cross-border Healthcare: EPF Position Statement. 2016 April. Available online: http://www.eu-patient.eu/ globalassets/policy/cross-borderhealthcare/epf_position statement_cbhc_220416.pdf.

5. Johnson B. Vytenis Andriukaitis calls for paradigm shift in health policy thinking. The Parliament. 2015 September 22. Available online: https://www.theparliamentmagazine. eu/articles/interview/vytenis-andriukaitis-calls-paradigmshift-health-policy-thinking

6. Health 2020. The European policy for health and wellbeing. World Health Organization (WHO). 2012, September 20. Available online: http://www.euro.who.int/ en/health-topics/health-policy/health-2020-the-europeanpolicy-for-health-and-well-being/about-health-2020

7. Morris M, Powick A, de Vettori E, et al. Deloitte 2016 Global Healthcare outlook: Battling costs while improving care. 2016. Available online: https://www2.deloitte.com/ content/dam/Deloitte/global/Documents/Life-SciencesHealth-Care/gx-lshc-2016-health-care-outlook.pdf

8. House J. Five Takeaways from New GDP-by-Industry Report. The Wall Street Journal, 2014, April 25. Available online: http://blogs.wsj.com/economics/2014/04/25/fivetakeaways-from-new-gdp-by-industry-report/. 
9. Reh G. 2015 Global life sciences outlook: Adapting in an era of transformation, Deloitte Touche Tohmatsu Limited, 2014. Available online: https://www2.deloitte.com/global/ en/pages/life-sciences-and-healthcare/articles/2015global-life-sciences-outlook.html

10. Snyder G. Next-generation "smart" MedTech devices: Preparing for an increasingly intelligent future, Deloitte Center for Health Solutions, 2015. Available online: http:// www2.deloitte.com/us/en/pages/life-sciences-and-healthcare/articles/smart-medtech-increasingly-intelligentfuture.html

11. Kaul R. With 105 centres, govt spreads telemedicine network across country, 2016, August 17. Hindustan Times. Available online: http://www.hindustantimes. com/india-news/with-105-centres-govt-spreadstelemedicine-network-across-country/storyUDwyqZRniQOjzJg9MOzk8I.html

12. Smith J, Vogenberg FR. Key Strategic trends that impact healthcare decision-making and stakeholder roles in the new marketplace. Am Health Drug Benefits 2015;8:15-20.

13. Berwick DM, Nolan TW, Whittington J. The triple aim: care, health, and cost. Health Aff (Millwood) 2008;27:759-769.

14. Gerhardt W, Korenda L, Morris M, et al. The road to value-based care: Your mileage may vary. Deloitte University Press. Deloitte Center for Health Solutions, 2015, March 20. Available online: https://dupress.deloitte. com/dup-us-en/industry/life-sciences/value-based-caremarket-shift.html

15. Starr P. The Social Transformation of American Medicine. NY: Basic Books 1982.

16. Levy D. Emerging mHealth: Paths for growth, 2012.

doi: $10.21037 /$ mhealth.2017.09.03

Cite this article as: Malvey DM, Slovensky DJ. Global mHealth policy arena: status check and future directions. mHealth 2017;3:41.
Available online: https://www.pwc.com/gx/en/healthcare/ mhealth/assets/pwc-emerging-mhealth-full.pdf

17. Wike K. 90\% of Executives Pursuing Telemedicine. Health IT Outcomes, 2014, November 14. Available online: https://www.healthitoutcomes.com/doc/90-ofexecutives-pursuing-telemedicine-0001

18. Jacobson S, Wang T. How laws and policies are shaping telemedicine. Rock Health, 2015, February 08. Available online: https://rockhealth.com/how-laws-policies-shapingtelemedicine-market/

19. American Medical Association. Issue Brief: Interstate Medical Licensure Compact. AMA Advocacy Resource Center, 2017. Available online: https://www.ama-assn.org/ sites/default/files/media-browser/specialty\%20group/arc/ fsmb-interstate-medical-licensure-compact-issue-brief.pdf

20. Trinh S, Zamanian K. China Poised to Overtake U.S. and Japan as top Telemedicine Market. Med Device Online. 2017 May 29. Available online: https://www. meddeviceonline.com/doc/china-poised-to-overtake-u-sand-japan-as-top-telemedicine-market-0001

21. Tithecott A, Sochacki C. (Oct. 2015) eHealth and telemedicine in the Gulf: a two-part guide. Digital Health Legal, 2(10), 2015, October. Available online: http://www. e-comlaw.com/ehealth-law-and-policy/

22. Frenk J. Dimensions of health system reform. Health Policy 1994;27:19-34.

23. The Commonwealth. A systems framework for healthy policy. (2016, October 31). Available online: https://www. thecommonwealth-healthhub.net/systems-frameworkhealthy-policy/

24. The Commonwealth. About us. Available online: http:// thecommonwealth.org/about-us 